\title{
Geoprocessamento aplicado à identificação de áreas aptas para implantação de pivôs
}

\section{centrais}

Geoprocessing applied to the identification of areas suitable for the implementation of central pivots

Geoprocesamiento aplicado a la identificación de áreas aptas para la implementación de pivotes centrales

\section{Resumo}

Com o crescimento populacional, há o aumento da demanda por alimentos, tornado a irrigação uma tecnologia importante para este fim. Portanto, o planejamento e o conhecimento técnico das variáveis ambientais são imprescindíveis para a implantação da irrigação, facilitado pelas técnicas de geoprocessamento, podendo auxiliar nas tomadas de decisões, principalmente pela capacidade e facilidade de trabalhar grandes áreas. Este trabalho objetivou identificar as áreas com aptidão à implantação de sistemas de irrigação por pivô central no município de Lagoa Grande - MG. Foram utilizados dados do Mapbiomas, IDE-Sisema e USGS, mediante técnicas de geoprocessamento, observando restrições técnicas e legais, e aplicando a sobreposição ponderada de dados. Como resultado, constatou-se que o município possui 7,9\% de sua área irrigada por pivô central. Em uma análise geral, o município possui 71,58\% da sua área com alguma aptidão para a ampliação da agricultura irrigada via pivô central. As ferramentas de análises espaciais através do SIG demonstraram ser eficientes na manipulação e integração dos dados utilizados para identificação e quantificação das áreas aptas a implantação de sistema de irrigação por pivô central, podendo ser uma alternativa viável para tomadas de decisões.

Palavras-chave: Geotecnologias; Análise multicritério; Agricultura irrigada; Aptidão agrícola.

\begin{abstract}
With population growth, there is an increase in demand for food, making irrigation an important technology for this purpose. Therefore, the planning and technical knowledge of environmental variables are essential for the implementation of irrigation, facilitated by geoprocessing techniques, and can help in decision making, mainly due to the ability and ease of working large areas. This work aimed to identify the areas with aptitude for the implementation of irrigation systems by central pivot in the municipality of Lagoa Grande - MG. Data from Mapbiomas, IDE-Sisema and USGS were used, using geoprocessing techniques, observing technical and legal restrictions, and applying weighted data overlap. As a result, it was found that the municipality has $7.9 \%$ of its area irrigated by central pivot. In a general analysis, the municipality has $71.58 \%$ of its area with some aptitude for the expansion of irrigated agriculture via central pivot. The spatial analysis tools through the GIS proved to be efficient in the manipulation and integration of the data used to identify and quantify the areas suitable for the implementation of a central pivot irrigation system, which can be a viable alternative for decision-making.
\end{abstract}

Keywords: Geotechnologies; Multicriteria analysis; Irrigated agriculture; Agricultural aptitude.

\section{Resumen}

Con el crecimiento de la población, hay un aumento en la demanda de alimentos, por lo que el riego es una tecnología importante para este propósito. Por lo tanto, la planificación y el conocimiento técnico de las variables ambientales son 
esenciales para la implementación del riego, facilitado por técnicas de geoprocesamiento, y pueden ayudar en la toma de decisiones, principalmente debido a la capacidad y facilidad de trabajo de grandes áreas. Este trabajo tuvo como objetivo identificar las áreas con aptitud para la implementación de sistemas de riego por pivote central en el municipio de Lagoa Grande - MG. Se utilizaron datos de Mapbiomas, IDE-Sisema y USGS, utilizando técnicas de geoprocesamiento, observando restricciones técnicas y legales, y aplicando superposición de datos ponderada. Como resultado, se encontró que el municipio tiene el 7,9\% de su superficie regada por pivote central. En un análisis general, el municipio cuenta con el 71,58\%de su superficie con alguna aptitud para la expansión de la agricultura de regadío a través del pivote central. Las herramientas de análisis espacial a través de SIG han demostrado ser eficientes en la manipulación e integración de datos utilizados para la identificación y cuantificación de áreas aptas para la implementación de un sistema de riego de pivote central, y pueden ser una alternativa viable para la toma de decisiones. Palabras clave: Geotecnologias; Análisis multicriterio; Agricultura de regadío; Aptitud agrícola.

\section{Introdução}

A prática da irrigação no mundo ocorre desde a pré-história, onde o homem desviava cursos d'água para irrigar suas plantações, o que possibilitou o estabelecimento humano em regiões secas como ao longo do rio Nilo no Egito e nos rios Tigre e Eufrates na Mesopotâmia (Testezlaf, 2017).

No Brasil, a irrigação teve início na década de 1900 no Rio Grande do Sul para o cultivo de arroz, intensificando-se em outras regiões do país a partir das décadas de 1970 e 1980, impulsionado pela expansão agrícola associada a escassez contínua de água, como no Semiárido brasileiro, onde parte importante da agricultura só se viabiliza mediante a aplicação artifícial de água (ANA, 2019).

Em um contexto geral, a agricultura irrigada se beneficia de quatro métodos de irrigação, podendo ser agrupados de acordo com a sua forma de aplicação da água, sendo a irrigação por superfície, subterrânea, por aspersão e localizada (Testezlaf, 2017).

Dentre os sistemas de irrigação, o pivô central está entre os mais populares e utilizados na agricultura Brasileira, cuja projeção para 2040 é de 4,2 milhões de hectares irrigados (ANA, 2021). Este método de irrigação teve seu primeiro registro aqui no Brasil em 1979, sendo instalado na bacia do rio Tietê no município de Brotas, em São Paulo, cuja capacidade, irrigava uma área de 76 hectares (ANA, 2019).

No levantamento realizado por Guimarães e Landau (2020) utilizando técnicas de geoprocessamento, identificou-se 22.292 pivôs centrais em todo território brasileiro no ano de 2020, perfazendo uma área irrigada de 1.612.617,3 ha. Segundo os autores o estado de Minas Gerais detém o maior número de equipamentos de irrigação do tipo pivô central, com uma área de 501.183,6 ha irrigada distribuída em 8.541 unidades de equipamentos de pivôs centrais. Entre os municípios com maior área irrigada por pivôs centrais no Brasil destacam-se os municípios de Paracatu-MG 72.726 ha e Unaí-Mg 71.573 ha. Já no estado de Goiás o município Cristalina se destaca com 62.355 ha.

O geoprocessamento pode ser definido como um conjunto de técnicas e métodos teóricos e computacionais relacionados com a coleta, entrada, armazenamento, tratamento e processamento de dados georreferenciados, ou seja, possuem uma posição específica no globo terrestre por meio de suas coordenadas geográficas (Zaidan, 2017).

O planejamento adequado de uma propriedade rural se torna necessário para quem quer usar a terra tomando decisões mais assertivas (Ângelo et al., 2017). Neste contexto, o geoprocessamento tem se mostrado uma ferramenta importante, permitindo ao homem do campo informações mais amplas, precisas e com maior agilidade (Matsushita, 2014). Sua aplicação permite a identificação de áreas propícias ao cultivo de café (Ferreira et al., 2021), Identificação de áreas potenciais para implantação de irrigação por pivô central (Barros et al., 2020), mapeamento de áreas irrigadas por pivô (Albuquerque et al., 2020), dentre várias outras aplicações ao meio rural, fornecendo dados técnicos que auxiliam os produtores nas tomadas de decisões (Waldner et al., 2021) 
Diante deste contexto, o presente estudo tem como objetivo identificar as áreas com aptidão à implantação de sistemas de irrigação por pivô central no município de Lagoa Grande - MG mediante técnicas de geoprocessamento.

\section{Metodologia}

Na perspectiva de Aragão e Neta (2017), o método de abordagem deste estudo se caracteriza como pesquisa quantitativa, pois visa a verificação, a demonstração através de testes estatísticos e da lógica matemática. Analisando os objetivos, essa pesquisa é exploratória (Pereira et al., 2018). Em relação aos procedimentos técnicos é do tipo estudo de caso (Zambello et al., 2018).

\section{1 Área de estudo}

A área de estudo corresponde ao município de Lagoa Grande (Figura 1), localizado na região noroeste do estado de

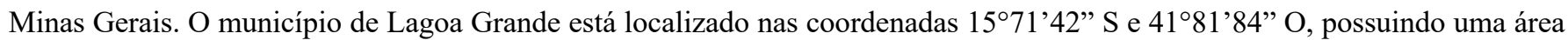
territorial de $1.236,301 \mathrm{~km}^{2}$, com clima tropical de altitude, com altitude de 947 metros. O município apresenta uma população total de 9.608 habitantes, com densidade populacional de 6,98 hab. $\mathrm{km}^{-2}$ (IBGE, 2017).

Figura 1 - Mapa de localização do município de Lagoa Grande-MG no contexto estadual.

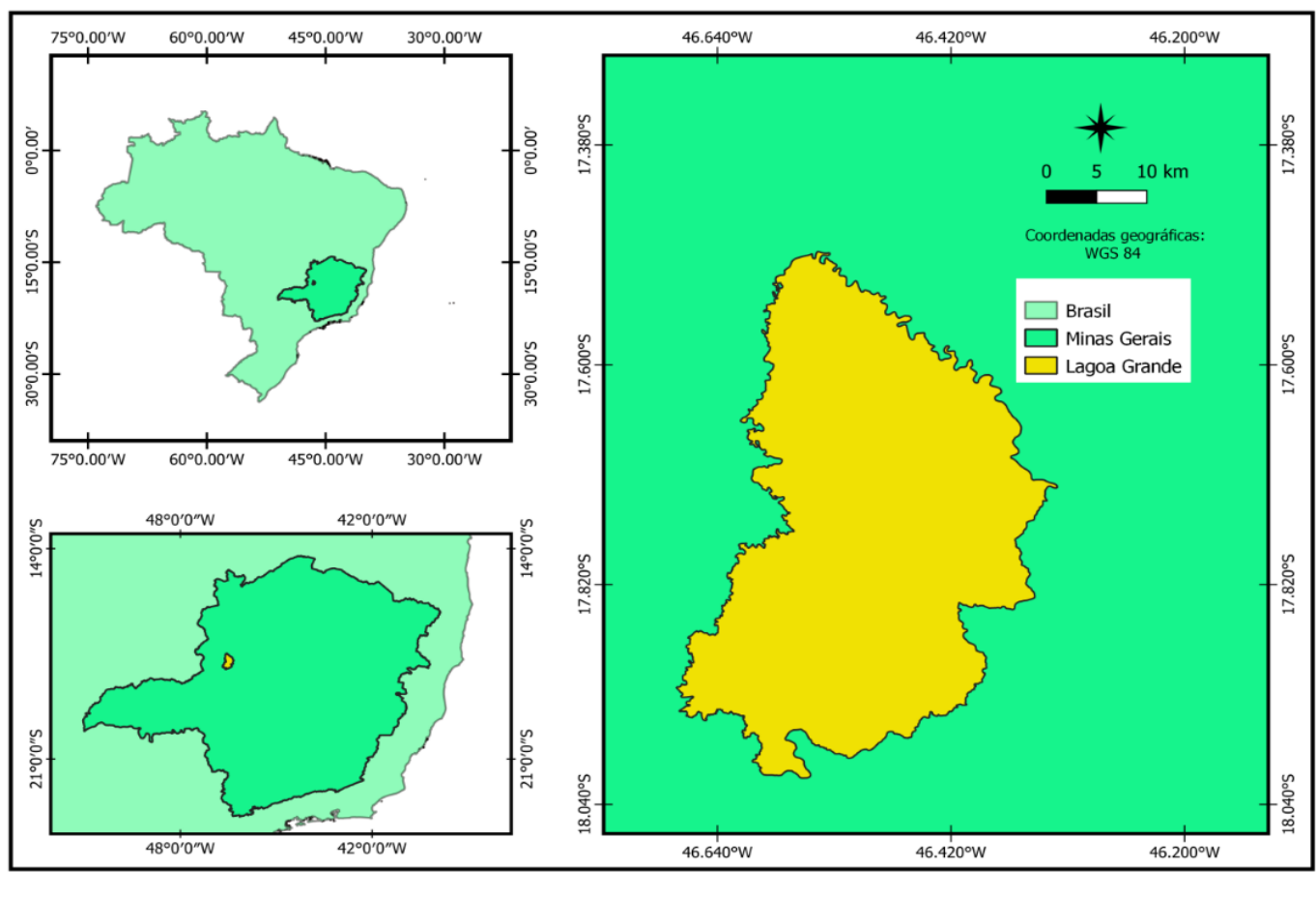

Fonte: Autores.

\subsection{Camadas de informações e dados cartográficos}

Esse estudo foi realizado com o auxílio do software livre QGIS 3.10.11 para manipular os dados vetoriais como pontos, linhas e polígonos além de dados matriciais. Na análise multicritério para tomada de decisão foram considerados quatro variáveis, as quais são pré-requisitos para se viabilizar a irrigação por sistema de pivô central, sendo elas, uso e ocupação do solo, distância do corpo hídrico, declividade do terreno e classes de solo (Barros et al., 2020). 
Os dados espaciais vetoriais das classes de solos foram obtidos através de arquivo no formato shapefile na plataforma digital do Instituído Brasileiro de Geografia e Estatísticas (IBGE, 2018). Os dados vetoriais foram recortados com o limite de município de Lagoa Grande-MG, no qual apresentou as classes de solos dos Latossolos, Cambissolos e Neossolos.

Os Latossolos possuem boa profundidade, textura média e argilosa, variam de fortemente a bem drenados. Os Cambissolos abrangem solos minerais com características variáveis, mas sempre apresentam textura média a fina, com pequena profundidade e elevado teor de minerais primários. Já os Neossolos são solos com pequeno desenvolvimento pedogenético, constituídos de material mineral ou por material orgânico com menos de $20 \mathrm{~cm}$ de espessura, possuem textura arenosa e presença de pedregulhos (Embrapa, 2013).

Com base nas informações descritas, as classes de solos foram reclassificadas através da tabela de atributos com valores correspondentes ao grau de importância, onde, os pesos foram atribuídos de acordo com as características mais favoráveis a agricultura em um contexto geral (Tabela 1).

Tabela 1 - Classe de solos, principais características e respectivos pesos referentes à aptidão para a instalação de irrigação por pivô central.

\begin{tabular}{ccc}
\hline Classe de solos & Atributos & Peso (9-1) \\
\hline Latossolos & Maduros, profundos e estruturados & 9 \\
Cambissolos & Rasos com alto teor de minerais e pedregoso & 5 \\
Neossolos & Raso e pedregoso & 1 \\
\hline
\end{tabular}

Fonte: Adaptado de Gomes et al. (2017).

Os dados de uso e cobertura do solo foram adquiridos pelo portal do MapBiomas, coleção 5 e ano base 2019, dados estes, no formato shapefile. Foi necessário fazer a correção da geometria pela ferramenta GRASS e o recorte vetorial para área de estudo e agrupados em classes pela ferramenta dissolver. Em sequência foi realizada a projeção da camada para o sistema de coordenadas SIRGAS 2000 e projeção UTM zona 23S. Os dados foram trabalhados respeitando as classes definidas com possibilidades agrícolas e não aplicável a agricultura (Tabela 2).

Tabela 2 - Classe de uso e cobertura do solo e respectivos pesos referentes a aptidão para a instalação de irrigação.

\begin{tabular}{cccc}
\hline Atributos & Características & Peso (9 -1) \\
\cline { 1 - 1 } \cline { 3 - 4 } Agrícola & Agricultura, pastagem e solo exposto & 9 \\
Não agrícola & & Área urbana, vegetação natural e corpos d'água & Restrito \\
\hline
\end{tabular}

Fonte: Autores.

Para a elaboração da camada de distância de corpos hídricos foram utilizados dados da hidrografia de Minas Gerais, dados estes, decorrentes do Mapeamento de uso da terra para o Cerrado e Mata Atlântica, por meio de imagens do satélite RapidEye com resolução espacial de 5m, no qual, disponibilizado pelo MapBiomas (MapBiomas, 2019).

Através dos dados de hidrografia seccionada para o município, foi aplicado o algoritmo Multi Ring Buffer, responsável por criar múltiplas áreas equidistantes em torno dos recursos de entrada que não se sobrepõem. Portanto, as distâncias aos corpos hídricos se relacionam ao custo de implantação do sistema de irrigação via pivô central, pois, quanto mais distante, mais oneroso o custo com motobombas e tubulações (Martins et al., 2015).

Portanto, as classes de distância da fonte hídrica, assim como, os seus respectivos pesos, foram definidas em função do custo de implantação do sistema (Tabela 3). 
Tabela 3 - Classes de distância de corpos hídricos e pesos para a implantação de irrigação por pivô central.

\begin{tabular}{ccc}
\hline Distância de corpo hídrico (m) & Características & Peso (9 -1) \\
\hline a 1.000 & Baixo custo com implantação & 9 \\
1.000 a 2.000 & Médio custo de implantação & 7 \\
2.000 a 4.000 & Alto custo de implantação & 5 \\
$<4.000$ & Elevado custo de implantação & 3 \\
\hline
\end{tabular}

Fonte: Adaptado de Martins et al. (2015).

A Lei N ${ }^{\circ} 12.651 / 2012$, define que se deve manter como Área de Preservação Permanente (APP) as faixas marginais de qualquer curso d'água natural perene e intermitente, variando de acordo com a largura do curso hídrico. Nessa análise foi considerada uma APP de 30 metros em todos os corpos hídricos, elaborado através da camada vetorial da hidrografia do município e considerado como restrita ao estudo.

Outra restrição aplicada, foi a Faixa de Domínio, faixa esta, não-edificável e com de $15 \mathrm{~m}$ de cada lado de rodovias e ferrovias amparada pela Lei $\mathrm{N}^{\circ} 6.766 / 79$. Portanto, foi adotado $15 \mathrm{~m}$ para ambos os lados das rodovias estaduais e municipais. Dados estes, adquiridos pelo catálogo digital IDE-Sisema (2012).

Para implantação de pivôs centrais, é recomendável declividade até 15\%, contudo, mediante ajuste na distância entre vãos, podem ser instalados com uma declividade máxima de até 30\% (Oldoni, 2018).

A declividade da área de estudo foi gerada a partir de dados Shuttle Radar Topographic Mission (SRTM) da NASA, adquiridas no United States Geological Survey (USGS). Portanto, para cobrir a área de estudo, foi elaborado um mosaico com três imagens e posteriormente executado o Modelo Digital de Elevação (MDE). Logo em seguida foi extraída a declividade em porcentagem através da ferramenta raster analise declividade, e através da ferramenta raster r.reclass fez a reclassificação da declividade (Tabela 4).

Tabela 4 - Classes de declividade e pesos para cada intervalo referente a aptidão para a instalação de sistema de irrigação por pivô central.

\begin{tabular}{cccc}
\hline Declividade (\%) & Atributo & Peso (9 - 1) \\
-5 & Ótimo & Bom & 9 \\
$15-30$ & Médio & 7 \\
$>30$ & Ruim & 3 \\
\hline
\end{tabular}

Fonte: Autores.

As classes de declividade e os pesos a ela atribuído, partiu da premissa da viabilidade de operação e instalação do sistema pivô central.

\subsection{Analytic Hierarchy Process (AHP)}

Proposto por Saaty no início dos anos 70, o método de Processo Analytic Hierarchy Process (AHP) permite lidar com o intuitivo, o racional e o irracional ao mesmo tempo quando se refere à tomada de decisão. É um método que podemos usar para integrar nossas percepções e propósitos em uma síntese geral (Santos \& Cruz, 2013). Os julgamentos de comparação de pares na escala do (AHP) para tomada de decisão varia de 1 a 9 (Tabela 5). Sendo que o valor 1 configura em áreas "menos 
aptas", enquanto o valor 9 indica áreas "mais aptas", e áreas que não são permitidas a implantação do sistema, como áreas urbanas, foram reclassificadas neste estudo como "restrita".

Tabela 5 - Escala fundamental de Saaty (1980).

\begin{tabular}{|c|c|c|}
\hline $\begin{array}{c}\text { Intensidade da } \\
\text { importância da escala } \\
\text { absoluta }\end{array}$ & Definição & Justificativa \\
\hline 1 & Igual importância & $\begin{array}{c}\text { As duas atividades contribuem equitativamente para o } \\
\text { objetivo }\end{array}$ \\
\hline 3 & $\begin{array}{l}\text { Importância moderada de um } \\
\text { sobre o outro fator }\end{array}$ & $\begin{array}{c}\text { Julgamento e experiência favorecendo fortemente uma } \\
\text { atividade sobre a outra }\end{array}$ \\
\hline 5 & Essencial ou forte importância & $\begin{array}{c}\text { Julgamento e experiência favorecendo fortemente uma } \\
\text { atividade sobre a outra }\end{array}$ \\
\hline 7 & Importância muito forte & $\begin{array}{l}\text { Uma atividade é fortemente favorecida e sua } \\
\text { dominância é demonstrada na prática }\end{array}$ \\
\hline 9 & Importância Extrema & $\begin{array}{l}\text { Evidência favorecendo uma atividade sobre a outra é a } \\
\text { mais expressiva possível na ordem de afirmação }\end{array}$ \\
\hline $2,4,6,8$ & $\begin{array}{l}\text { Valores intermediários entre os } \\
\text { julgamentos adjacentes }\end{array}$ & Quando há necessidade de compromisso \\
\hline
\end{tabular}

Fonte: Adaptada (Saaty, 1980).

\subsection{Análise espacial e mapa de aptidão agrícola}

As camadas avaliadas foram reclassificadas, recebendo pesos de acordo com a sua especificidade, seguindo a escala fundamental de Saaty (1984).

Após as etapas de análises espaciais com suas respectivas reclassificações, foi aplicado o método de análise multicritérios através da sobreposição ponderada das quatro camadas (Tabela 6).

Tabela 6 - Ponderação de importância das camadas para a instalação de sistema de irrigação por pivô central.

\begin{tabular}{ccc}
\hline Camada & Importância (\%) \\
\hline Declividade & & 35 \\
Distância de corpos hídricos & 35 \\
Classes de solo & 20 \\
Uso e cobertura do solo & 10 \\
\hline
\end{tabular}

Fonte: Adaptado de Martins et al. (2015) e Gomes et al. (2017).

Esse procedimento sobrepõe vários arquivos rasters usando uma escala de medição comum e ponderando cada um de acordo com a sua importância, definindo o problema, dividindo o modelo em submodelos e identificando as camadas de entrada (ESRI, 2019).

Após a análise multicritério foi necessária a reclassificação do mapa de aptidão para extrair as áreas aptas, inaptas e moderadamente aptas. Esse arquivo com as informações matricial foi convertido em vetorial através da ferramenta converter raster para vetor, originando o mapa final de aptidão de implantação de pivôs centrais no município de Lagoa Grande. Em seguida, foi extraído pela tabela de atributos as áreas de cada classe, aptas, inaptas e moderadamente aptas, assim como, a quantidade de área de cada classe. 


\subsection{Pivôs centrais instalados no município}

A camada vetorial shapefile dos recortes dos pivôs centrais foi obtida através dos arquivos de ano base 2020 do portal da Embrapa (Geoinfo, 2020). O arquivo foi reprojetado para o sistema de coordenadas (SIRGAS 2000 / UTM zone 23s) e posterior, foi realizado o recorte utilizando a ferramenta recorte de vetor para a área de estudo. Os polígonos dos pivôs centrais foram calculados através da camada de atributo. Em seguida extraída a quantidade de área de pivôs centrais já existentes nas três classes, aptas, moderadamente aptas e inaptas.

\section{Resultados e Discussão}

Na Figura 2, pode ser observado a ocorrência de Latossolos predominantes em toda área do município, cerca de 87786,80 ha, seguido pelo Neossolos com 32355,38 ha e por fim, os Cambissolos com cerca de 1750,31 ha.

Figura 2 - Classes de solos encontrados no município de Lagoa Grande-MG.

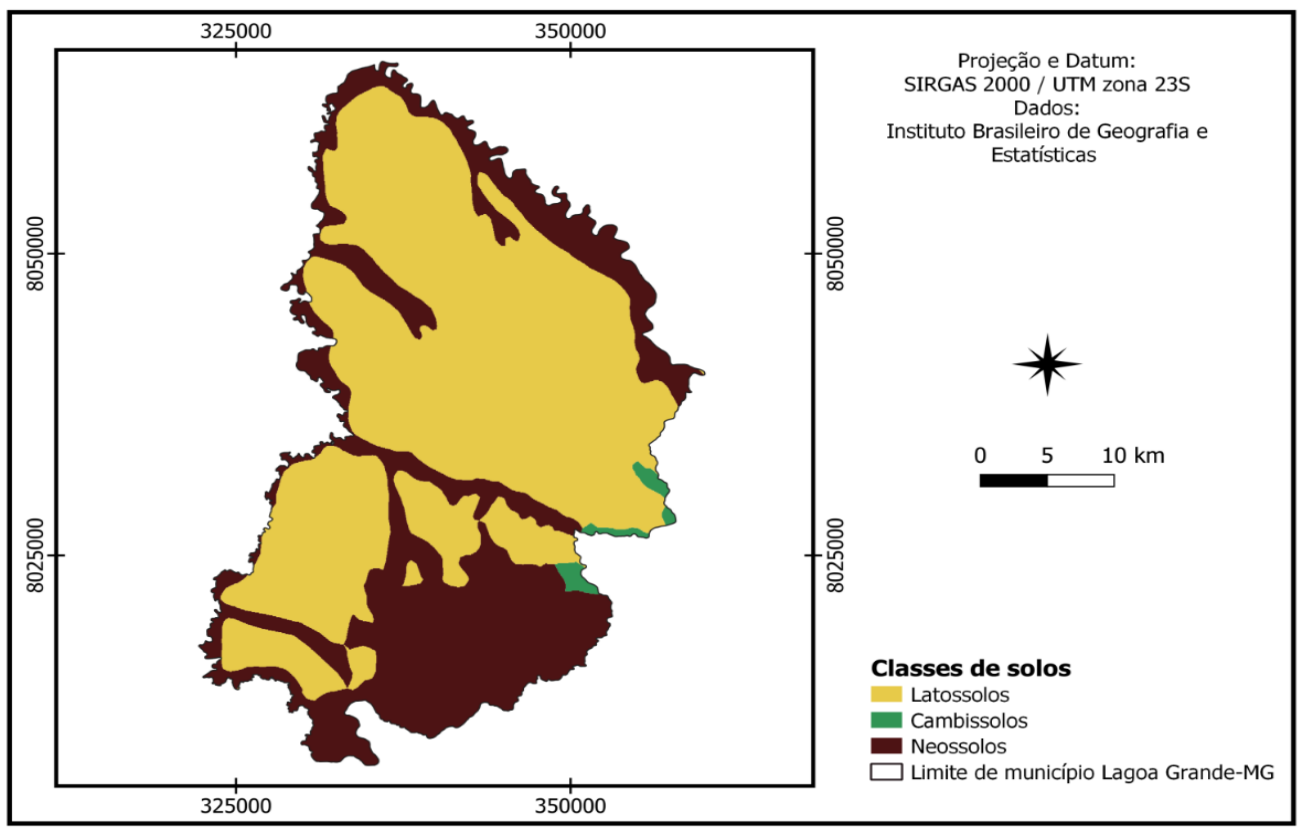

Fonte: Dados da pesquisa.

A Figura 3 apresenta o mapa do uso e cobertura do solo no município de Lagoa Grande, podendo ser observado 33639,64 ha de áreas consideradas como restrita, ou seja, áreas que apresentam florestas, corpos hídricos e vegetação natural. Portanto, neste quesito, o município possui 88252,84 ha com aptidão a agricultura. 
Figura 3 - Uso e cobertura do solo do município de Lagoa Grande-MG.

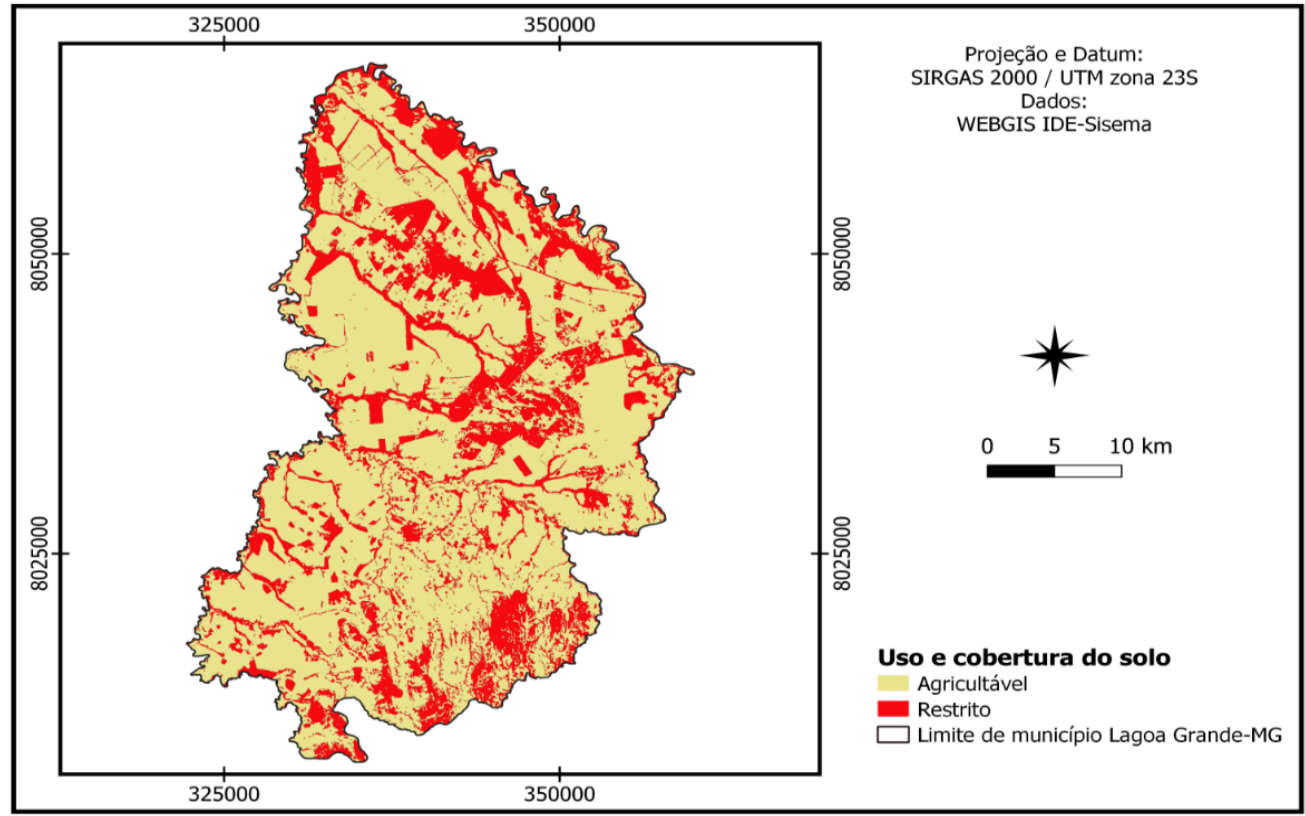

Fonte: Dados da pesquisa.

O mapa com as classes de distâncias de corpos hídricos (Figura 4), onde apenas 0,26\% do município apresentou distâncias superiores a 4.000 metros de cursos hídricos. O custo de implantação do sistema de pivô central está diretamente relacionado aos custos com tubulações, dimensionamento do sistema de bombeamento, reduzindo consequentemente a aptidão para grandes distâncias (Gomes et al., 2017).

Figura 4 - Distâncias de cursos hídricos no município de Lagoa Grande.

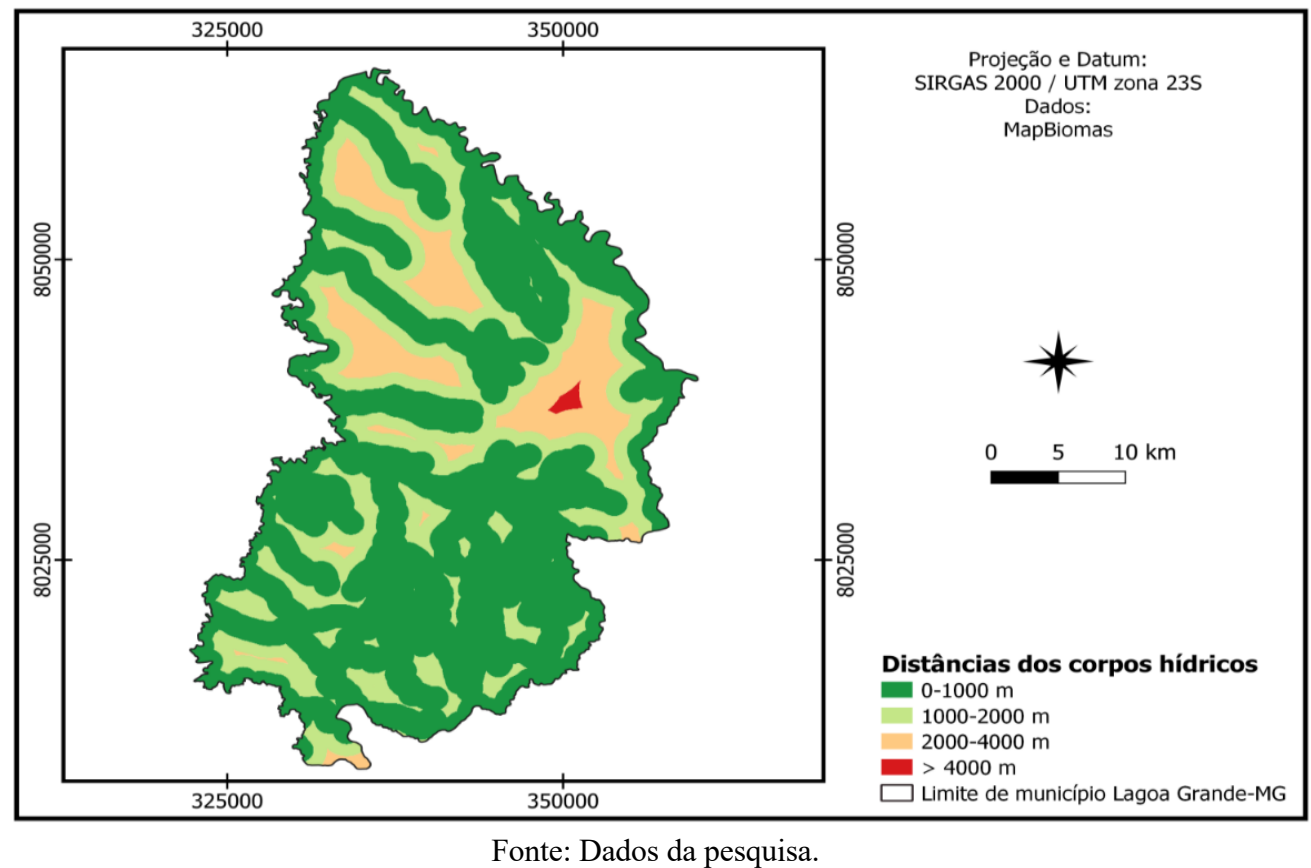

A Figura 5 apresenta as restrições ao estudo referente as APPs e faixa de domínio, visto que estas áreas não podem ser agricultáveis devido as legislações regentes, que somado, representa 4127,78 ha (3,86\% da área do município). 
Figura 5 - União das restrições referentes a APP e faixa de domínio.

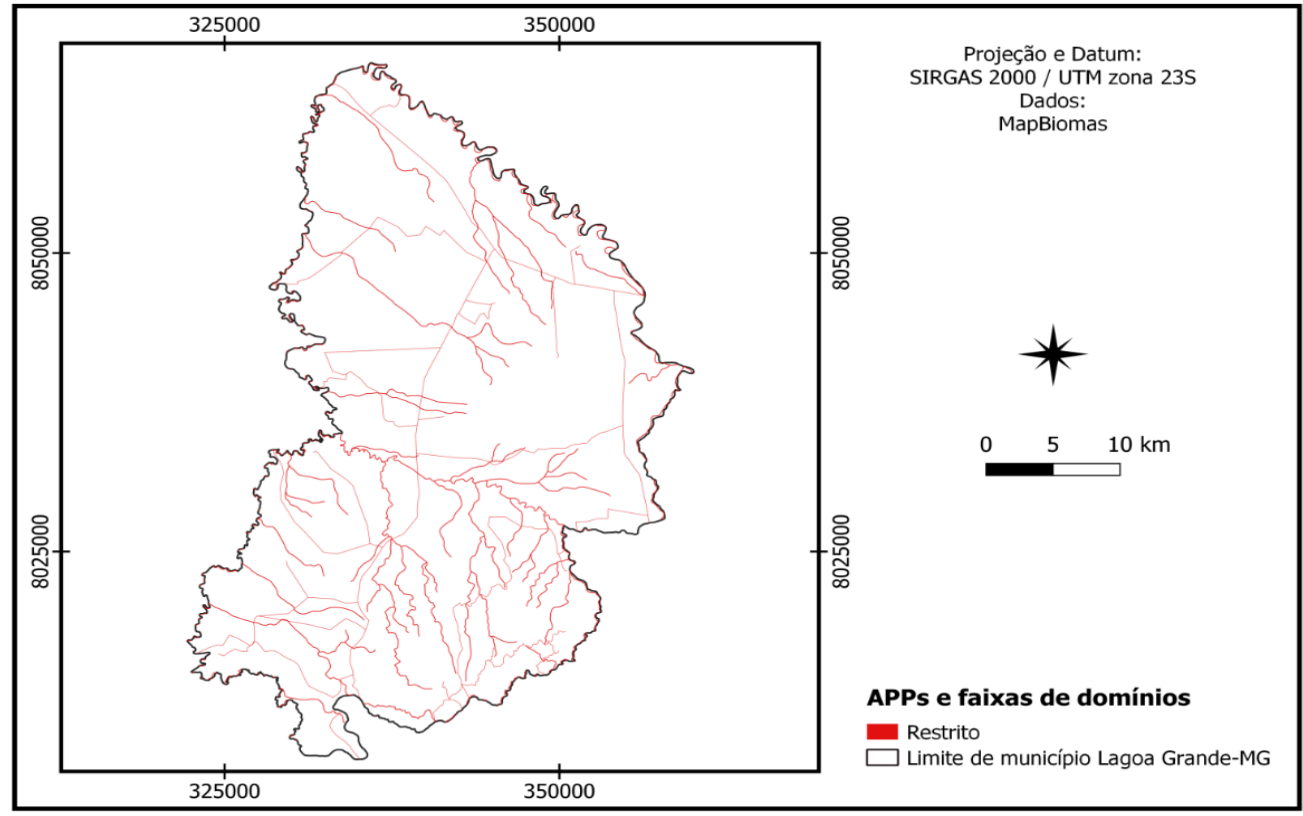

Fonte: Dados da pesquisa.

O relevo predominante no município de Lagoa Grande é plano, onde 97\% de suas áreas estão abaixo de 5\% de declividade (Figura 6), favorecendo a implantação do sistema de irrigação via pivô central baseado neste critério, ou seja, quanto mais plano, mais viável a implantação do sistema (Gomes et al., 2017).

Figura 6 - Declividade do município de Lagoa Grande.

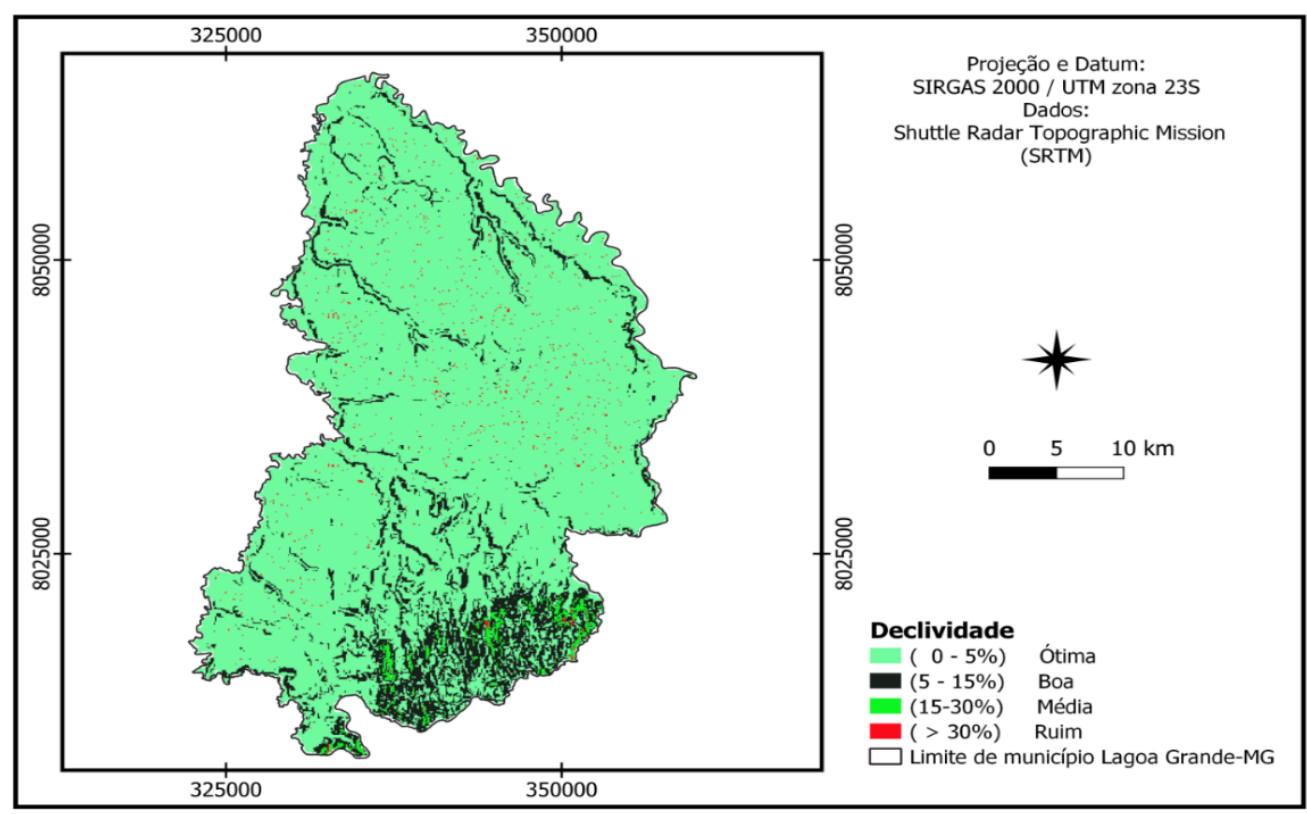

Fonte: Dados da pesquisa.

O mapa de aptidão para implantação de irrigação por pivô central no município de Lagoa Grande (Figura 7), mostra o resultado após a integração das camadas reclassificadas com seus respectivos pesos. Resultados estes, de acordo com as características de aptidão ótima, boa, média e ruim. 
Figura 7 - Mapa de aptidão para implantação de pivôs centrais no município de Lagoa Grande-MG.

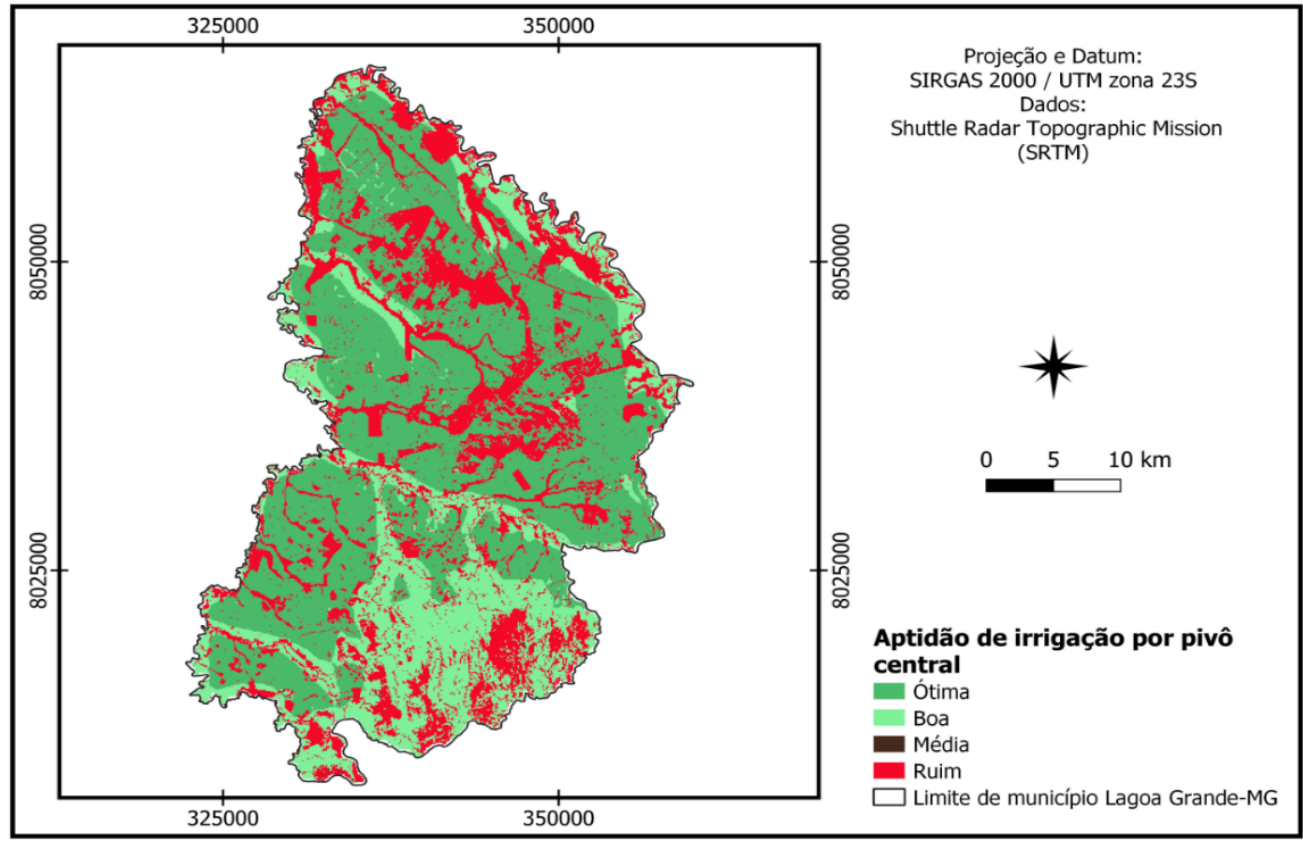

Fonte: Dados da pesquisa.

As áreas apontadas como aptidão ruim (Tabela 7), apresentam condições de restrição para utilização de pivôs centrais, representando praticamente $28,42 \%$ da área do município, enquanto, o somatório das classes com alguma aptidão a implantação do sistema de irrigação proposto, corresponde $71,58 \%$ da área município.

Tabela 7 - Área total de cada classe de aptidão para implantação de sistema de irrigação por pivô central.

\begin{tabular}{ccc}
\hline Classes de aptidão & Área (ha) & Porcentagem (\%) \\
\hline Ótima & $59.046,62$ & 48,97 \\
Boa & $27.230,59$ & 22,58 \\
Média & 31,58 & 0,03 \\
Ruim & $34.265,78$ & 28,42 \\
\hline
\end{tabular}

Fonte: Dados da pesquisa.

O município de Lagoa Grande possui 172 pontos pivôs centrais instalados (Figura 8), com uma área total irrigada de 8.549,6 ha. Sua proximidade com grandes cursos d'água como, por exemplo, os rios Paracatu, Prata, Manabuiú e Taperas, se torna um fator positivo a irrigação, contudo, apenas uma pequena parcela 7,9\% da área do município é equipada com pivôs centrais. Fato este, devido a principal atividade econômica do município basear na produção do leite, tornado a pecuária o setor mais forte (Pitorra \& Ferreira, 2018). 
Figura 8 - Pivôs centrais instalado no município de Lagoa Grande-MG no ano de 2020.

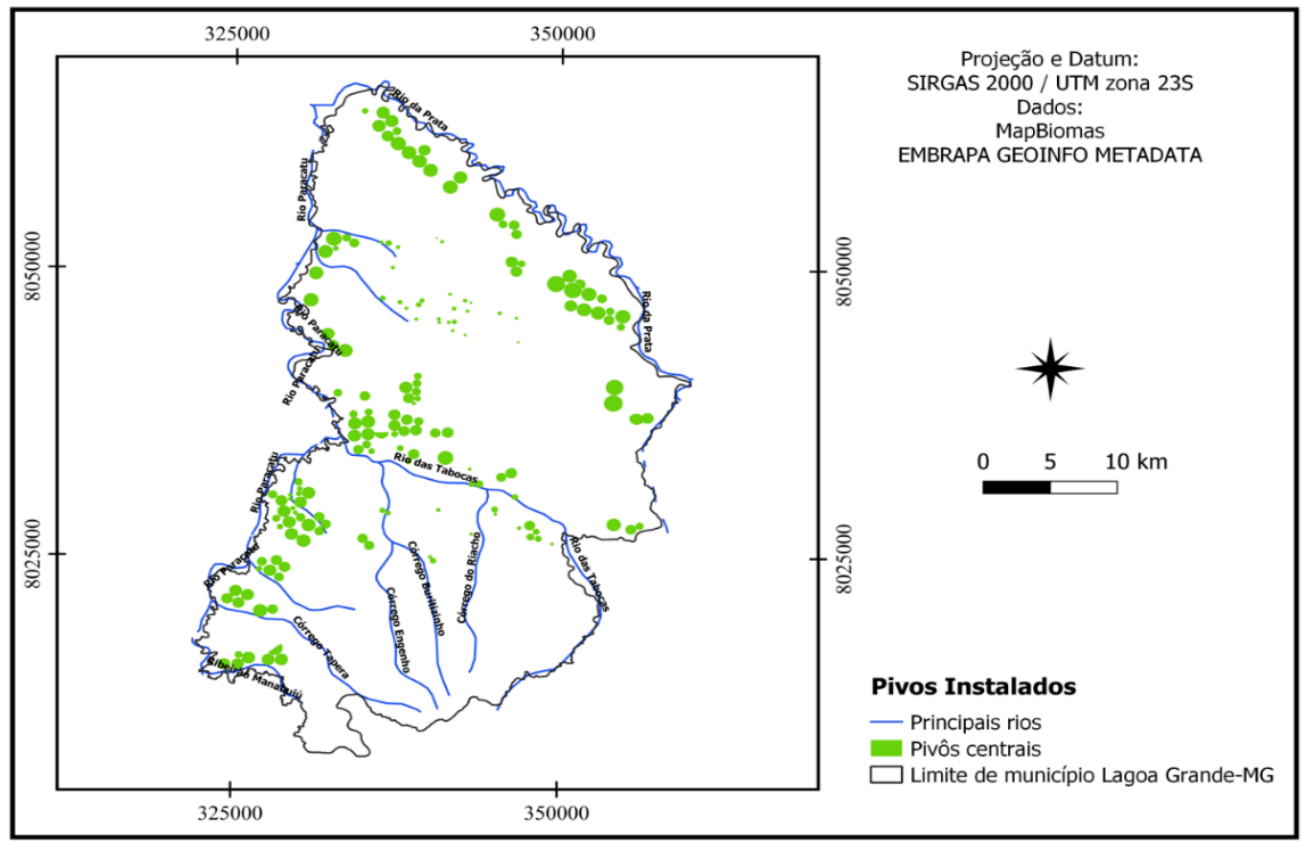

Fonte: Dados da pesquisa.

Como pode ser observado, seguindo a tendência economicamente viável, a maioria dos equipamentos de irrigação estão localizados na faixa das extremidades e no centro, onde estão localizados os rios Paracatu na extremidade a esquerda, Prata na extremidade a direita e o rio das Tabocas no centro.

Os dados da Tabela 8 demonstram que $86,6 \%$ dos pivôs instalados se encontram em áreas consideradas como ótimas seguindo todos os critérios avaliativos, e apenas $11,9 \%$ estão localizados nas áreas de classe boa.

Tabela 8 - Quantificação da área de cada classe ocupada por pivô central em Lagoa Grande no ano de 2020.

\begin{tabular}{ccc}
\hline Classes de aptidão & Área (ha) & Porcentagem (\%) \\
\hline Ótima & $7.403,77$ & 86,6 \\
Boa & $1.017,44$ & 11,9 \\
Média & 0,00 & 0,00 \\
Ruim & 127,92 & 1,5 \\
\hline
\end{tabular}

Fonte: Dados da pesquisa.

Uma pequena área que corresponde a $1,5 \%$ da classe ruim contempla pivôs instalados, fato este podendo ser decorrente dos pivôs serem instalados muito próximo das APPs.

Já a Tabela 9 apresenta as áreas de cada classe que ainda não foram ocupadas por pivô central, demonstrando a potencialidade do município ao sistema de irrigação proposto. 
Tabela 9 - Potencial de cada classe a implantação de irrigação por pivôs centrais.

\begin{tabular}{ccc}
\hline Classes de aptidão & Área (ha) & Porcentagem (\%) \\
\hline Ótima & $51.642,85$ & 87,46 \\
Boa & $26.213,15$ & 96,62 \\
Média & 31,56 & 100,00 \\
Ruim & $34.137,86$ & 99,63 \\
\hline
\end{tabular}

Fonte: Dados da pesquisa.

O conhecimento das características do campo pode ajudar a fomentar o setor agrícola, contribuindo para o aumento da produção de grãos (Waldner et al., 2021). Portanto, o mapeamento dessas características físicas pode favorecer a tomada de decisão para uma agricultura irrigada ((Waldner \& Diakogiannis, 2020).

O uso do geoprocessamento no estudo da agricultura irrigada tem proporcionado informações importantes para a produção vegetal. Pinhati et al. (2017) aplicou técnicas de interpretação visual utilizando mosaicos de imagens de satélite na bacia do rio São Marcos abrangendo áreas dos estados de Goiás, Minas Gerais e Distrito Federal para avaliar a capacidade da expansão da irrigação via pivô central. Gomes et al. (2017) aplicou técnicas de geoprocessamento através da análise multicritério no município de Santa Helena de Goiás para identificar áreas aptas a irrigação pelo sistema pivô central, e em uma escala maior, a aplicação de técnicas de geoprocessamento definindo áreas prioritárias para o fomento da agricultura irrigada em todo o território Brasileiro (FAO, 2017).

\section{Conclusão}

Conclui-se que o município de Lagoa Grande possui grande aptidão para implantação de sistemas de irrigação por pivô central.

As informações dos dados matriciais e vetoriais manipulados em ambiente SIG, possibilitaram a geração de informações que podem auxiliar na tomada de decisão quanto à implantação de pivôs centrais no município.

O município de Lagoa Grande possui um grande potencial a ser explorado na implantação de equipamentos de pivôs centrais, cerca de $71,58 \%$ de sua área territorial possui alguma aptidão ao sistema.

As ferramentas de análises espaciais através do SIG demonstraram ser eficientes na manipulação e integração dos dados utilizados para identificação e quantificação das áreas aptas a implantação de sistema de irrigação por pivô central, podendo ser uma alternativa viável para estudos de aptidão a irrigação.

Sugere-se para trabalhos futuros, uma análise da disponibilidade hídrica do município para correlacionar com os dados da aptidão física apresentada neste estudo.

\section{Referências}

Agência Nacional de Águas. (2019). Levantamento da agricultura irrigada por pivôs centrais no Brasil (1985 - 2017). (2a ed.), ANA.

Agência Nacional de Águas. (2021). Atlas irrigação: uso da água na agricultura irrigada. Agência Nacional de Águas. ANA.

Albuquerque, A. O., de Carvalho Júnior, O. A., Carvalho, O. L. F. D., de Bem, P. P., Ferreira, P. H. G., de Moura, R. D.S., Silva, C. R., Trancoso Gomes, R. A. \& Fontes Guimarães, R. (2020). Deep Semantic Segmentation of Center Pivot Irrigation Systems from Remotely Sensed Data. Remote Sensing, $12(13), 2159$.

Ângelo, A. R., Passos, E. \& Morais, J. L. (2017). Geoprocessamento aplicado à determinação da aptidão agrícola de terras: localidade de Serrinha, Paiçandu, estado do Paraná, Brasil. Ambiência Guarapuava, 13, 158-175.

Aragão, J. W. M. \& Neta, M. A. H. M. (2017). Metodologia Cientifica. UFBA.

ASF. (2021). Data search vertex. https://search.asf.alaska.edu/\#/?zoom=3.333\&center=-95.645,41.382 
Research, Society and Development, v. 10, n. 8, e6110817038, 2021

(CC BY 4.0) | ISSN 2525-3409 | DOI: http://dx.doi.org/10.33448/rsd-v10i8.17038

Barros, A. C., Minhoni, R. T. A., Lima, A. A. \& Barros, Z. X. (2020). Identificação de terras potenciais para irrigação por pivô central mediante técnicas de geoprocessamento. Brazilian Journal of Development, 6(5), 32329-32343.

Barros, A. C., Tagliarini, F. S. N., Minhoni, R. T. A., Garcia, Y. M., Barros, Z. X. \& Zimback, C. R. L. (2019). Mapeamento da aptidão agrícola das terras por meio de análise multicritério. Revista de Ciências Agrárias, 42(2), 1-10.

Brasil. (2012). Lei $n^{\circ}$ 12.651, de 25 de maio de 2012. http://www.planalto.gov.br/ccivil_03/_ato2011-2014/2012/lei/112651.htm

Empresa Brasileira de Pesquisa Agropecuária (2013). Sistema Brasileiro de Classificação de Solos - SiBCS. (3a ed.), Embrapa.

Ferreira, M. L., Andrade, A. M. de \& Santiago, W. E. (2021). Geoprocessamento aplicado à identificação de áreas propícias ao cultivo de café. Research, Society and Development, 10(4), 17410414050.

Food and Agriculture Organization of the United Nations. (2017). Agricultura Irrigada Sustentável no Brasil: Identificação de Áreas Prioritárias. FAO.

Geoinfo. (2020). Pivôs centrais no Estado de Minas Gerais em 2020. http://geoinfo.cnpms.embrapa.br/layers/geonode\%3Apivos_2020_uf_mg/metadata_read

Gomes, L. F., Soares, J. A. B., Santos, L. N. S. \& Giongo, P. R. (2017). Geotecnologias aplicada na identificação de áreas aptas a implantação de irrigação por pivô central no cerrado. In: IV Inovagri International Meeting.

Guimarães, D. P. \& Landau, E. C. (2020). Georreferenciamento dos Pivôs Centrais de Irrigação no Brasil: Ano Base 2020. Embrapa Milho e Sorgo.

IDE-SISEMA. (2012). Uso e cobertura da terra. Sisema: Modis 2012. https://idesisema.meioambiente.mg.gov.br/

Instituto Brasileiro de Geografia e Estatística. (2017). Cidades 2017. https://cidades.ibge.gov.br/brasil/mg/lagoa-grande/panorama

MapBiomas. (2019). Coleção 5 da Série Anual de Mapas de Cobertura e Uso de Solo do Brasil. https://mapbiomas.org/colecoes-mapbiomas1?cama_set_language=pt-B

Martins, R. N., Corte, W. C., Castelo Branco Neto, U. G., Santos, V. K. S. \& Nery, C. V. M. (2015). Identificação de áreas aptas a irrigação por pivô central no município de Paracatu-MG utilizando SIG e dados SRTM. In: I Simpósio Internacional de Águas, Solos e Geotecnologias.

Matsushita, M. S. (2014). Trabalhos da Extensão Rural com uso de Geoprocessamento. Instituto Emater.

Oldoni, L. V. (2018). Análise da aptidão para irrigação por pivô central e por gotejamento no Oeste do Paraná. INPE.

Pereira, A. S., Shitsuka, D. M., Parreira, F. J. \& Shitsuka, R. (2018). Metodologia da pesquisa cientifica. UAB/NTE/UFSM.

Pinhati, F. S. C., Souza, S. A. de \& Villela, W. M. C. (2017). Avaliação de um cenário de ampliação da irrigação na Bacia do Rio São Marcos por meio de geoprocessamento e desenvolvimento de ferramenta computacional para cálculo do balanço hídrico na escala de ottobacias. In: XXII Simpósio Brasileiro de Recursos Hídricos.

Pitorra, E. F. \& Ferreira, R.L. (2018). Princípios da sustentabilidade e desenvolvimento urbano no município de Lagoa Grande/MG. Humanidades \& Tecnologia, 12(12), 40-53.

Saaty, T. L. (1980). The Analytic Hierarchy Process. McGraw-Hill.

Santos, L, F. \& Cruz, R. B. C. (2013). O Uso do Método AHP na Tomada de Decisão para Seleção de Sistemas de Lajes de Edifícios Comerciais. Engenharia Estudo e Pesquisa, 13(1), 39-52.

Testezlaf, R. (2017). Irrigação: métodos, sistemas e aplicações. Unicamp/FEAGRI.

Waldner, F. \& Diakogiannis, F. I. (2020). Deep learning on edge: Extracting field boundaries from satellite images with a convolutional neural network. Remote Sensing of Environment, 245, 111741.

Waldner, F., Diakogiannis F. I., Batchelor, K., Ciccotosto-Camp, M., Cooper-Williams, E., Herrmann, C., Mata, G. \& Toovey, A. (2021). Detect, Consolidate, Delineate: Scalable Mapping of Field Boundaries Using Satellite Images. Remote Sensing, 13(11), 2197.

Zaidan, R. T. (2017). Geoprocessamento Conceitos e Definições. Revista de Geografia, 7(2), 195-201.

Zambello, A. V., Soares, A. G., Tauil, C. E., Donzelli, C. A., Fontana, F. \& Chotolli, W. P. (2018). Metodologia da pesquisa e do trabalho cientifico. FUNEPE. 